UDC 930.26 (470.45)

Submitted: 26.03.2017

LBC 63.48 (235)

\title{
FORMATION OF BURIAL MOUNDS OF THE SARMATIAN TIME IN THE BASIN OF THE ESAULOVSKY AKSAI RIVER ${ }^{1}$
}

Accepted: 01.06.2017

\author{
Elena A. Korobkova \\ Volgograd State University, Volgograd, Russian Federation
}

\begin{abstract}
The article deals with the features of the formation of the burial mounds in the basin of the Esaulovsky Aksai river in the Sarmatian period. Most of the burial mounds of the region begin to form in the Bronze Age and continue to function throughout the early, middle and early late-Sarmatian periods. Most of the burial mounds were located on the watersheds and above-flood terraces of different levels. All of them are characterized by same principles of planning, barrows in them are stretched in a chain in the natural form of the terrace on which the burial mound was built. The territories developed already in the Bronze Age were chosen for creating mounds in the early Sarmatian period. The main part of them is concentrated on a small section landplot of the middle course of the Esaulovsky Aksai river. During the Middle Sarmatian period, the main part of barrows were also located in the middle course of the Esaulovsky Aksai, but represented 2 plots. One of these plots continues to use large burial mounds of the previous period, and the other one undergoes the creation of small barrow groups consisting usually of two-three barrows containing the richest burials of the region with the "classical" set of Middle Sarmatian features. In the late Sarmatian period, as well as in the previous stages of the Sarmatian culture, the burial mounds of the middle course of the Esaulovsky Aksai continue to be used, which cease to function no later than at the first half of the $3^{\text {rd }}$ century AD. But the territory of actively used burial mounds changes, and the main complexes of that time concentrate in the upper reaches, where new burial mounds are created and continue to function until the end of the Sarmatian era.

Key words: archaeological monument, burial mound, Early Sarmatian culture, Middle Sarmatian culture, Late Sarmatian culture, Esaulovsky Aksai.

Citation. Korobkova E.A. Formation of Burial Mounds of the Sarmatian Time in the Basin of the Esaulovsky Aksai River. Vestnik Volgogradskogo gosudarstvennogo universiteta. Serija 4, Istorija. Regionovedenie. Mezhdunarodnye otnoshenija [Science Journal of Volgograd State University. History. Area Studies. International Relations], 2017, vol. 22, no. 3, pp. 36-41. (in Russian). DOI: https://doi.org/10.15688/jvolsu4.2017.3.3.
\end{abstract}

УДК $930.26(470.45)$

ББК 63.48 (235)
Дата поступления статьи: 26.03.2017 Дата принятия статьи: 01.06.2017

\section{ОСОБЕННОСТИ ФОРМИРОВАНИЯ КУРГАННЫХ МОГИЛЬНИКОВ САРМАТСКОГО ВРЕМЕНИ В БАССЕЙНЕ РЕКИ ЕСАУЛОВСКИЙ АКСАЙ ${ }^{1}$}

\footnotetext{
Елена Алексеевна Коробкова

Аннотация. В статье характеризуются особенности формирования курганных могильников в бассейне p. Есауловский Аксай в сарматский период. Большинство могильников региона начинают формироваться еще в эпоху бронзы и продолжают функционировать на протяжении ранне-, средне- и начала позднесарматского периодов. Основная масса курганных могильников находилась на водоразделах и надпойменных террасах разного уровня. Все могильники имеют одинаковые принципы планиграфии: курганы в них были вытянуты в цепочку, при этом использовалась естественная форма террасы, на которой сооружался могиль-
} 
ник. Для создания курганных насыпей в раннесарматский период выбирались территории, освоенные еще в эпоху бронзы. Основная же их часть сосредоточена на небольшом участке среднего течения р. Есауловский Аксай. В среднесарматское время большая часть курганов также располагалась в среднем течении Есауловского Аксая, но представляла из себя два участка: на одном из них продолжалось использование крупных курганных могильников, функционировавших еще в предыдущий период, на другом создавались небольшие курганные группы, состоявшие обычно из двух-трех курганных насыпей, содержавших наиболее богатые погребения региона с «классическим» набором среднесарматских признаков. В позднесарматский период, так же как и на предыдущих этапах сарматской культуры, продолжают использоваться курганные могильники среднего течения Есауловского Аксая, которые прекращают свое функционирование не позднее первой половины III в. н.э. А территория расположения активно используемых могильников меняется, основные комплексы этого времени сосредоточиваются в верхнем течении, где создаются новые могильники, которые продолжают функционировать до конца сарматской эпохи.

Ключевые слова: археологический памятник, курганный могильник, раннесарматская культура, среднесарматская культура, позднесарматская культура, Есауловский Аксай.

Цитирование. Коробкова Е. А. Особенности формирования курганных могильников сарматского времени в бассейне реки Есауловский Аксай // Вестник Волгоградского государственного университета. Серия 4, История. Регионоведение. Международные отношения. - 2017. - T. 22, № 3. - С. 36-41. - DOI: https:// doi.org/10.15688/jvolsu4.2017.3.3.

Территория Есауловского Аксая - один из наиболее изученных в археологическом отношении районов: здесь за 60 лет исследований были раскопаны 46 курганных могильников, содержавших 964 погребения различных эпох, большинство из которых относится к сарматскому времени (514 погребений) [1].

Нужно отметить, что к настоящему моменту полностью исследованы в основном только небольшие курганные группы состоявшие из не более чем десятка насыпей. В крупных могильниках обычно раскопаны либо несколько курганов (например, Аксай IV, Аксай V, Шургановы курганы и др.), либо по разным причинам неисследованными остаются несколько курганных насыпей (например, Перегрузное, Аксай I, Абганерово II и др.), что затрудняет реконструкцию особенностей формирования и планиграфии могильников.

Особенностям топографии и планиграфии курганных могильников различных эпох посвящен ряд статей или отдельные части монографических исследований $[4 ; 5 ; 9 ; 10 ; 13]$.

Есауловский Аксай представляет из себя небольшую степную извилистую речку протяженностью 222 км, берущую свое начало на западном склоне Ергенинской возвышенности (135 м), в течении которой можно условно выделить три участка: верхнее течение от истока до с. Гончаровка, среднее течение от с. Гончаровка до с. Заливское и нижнее течение от с. Заливское до впадения реки в Цимлянское водохранилище.
В степях Есауловского Аксая курганы начинают возводиться еще в эпоху энеолита, при этом насыпи этого времени встречаются в трех зонах бассейна р. Есауловский Аксай, но наибольшее их количество находится в ее среднем течении (могильник Перегрузное) [3].

В бронзовом веке освоение территорий в непосредственной близости от Есауловского Аксая происходит более интенсивно, создаются могильники, основная масса которых располагается в среднем течении реки.

Наиболее древние погребения раннего железного века относятся к савроматскому времени и сосредоточены в основном в двух могильниках в нижнем течении Есауловского Аксая [11].

Активное же формирование курганных могильников происходит в сарматскую эпоху. Из исследованных на сегодняшний день сарматских погребальных комплексов, к сожалению, не все памятники могут быть отнесены к определенному периоду сарматской культуры. Более $21 \%$ погребений в результате ограбления не содержат датирующего материала, дающего возможность отнести их к одному из этапов сарматской культуры.

Основная масса освоенных и маркированных курганными могильниками участков находилась на водоразделах и надпойменных террасах разного уровня. Лишь два могильника - Аксай I и Аксай II - были сооружены в поймах рек. Все могильники имеют одинаковые принципы планиграфии: использовалась 
естественная форма террасы, на которой сооружался могильник, и курганы были вытянуты в цепочку, обычно с востока на запад с незначительными отклонениями. Исключения составляют упомянутые выше могильники, расположенные в поймах рек. Так, могильник Аксай I представляет собой две отстоящие друг от друга курганные группы. Такая планиграфия обусловлена тем, что в центральной части могильника находится лиман, поросший камышом и делящий естественным образом могильник на две группы - восточную и западную. Курганные насыпи Аксая II расположены полукругом. Такое расположение курганов, как и в других группах, могло определяться географическими особенностями (например, разливами р. Россошь, рядом с которой и расположен могильник) или некими сакральными требованиями к подобному формированию пространства могильника.

Для создания курганных насыпей в раннесарматский период выбирались территории, освоенные еще в эпоху бронзы. Большинство курганов бронзового века в таких могильниках имеют впускные погребения раннесарматского времени. Исключением является Терновский курганный могильник, в котором нет погребений, предшествующих сарматской эпохе. Курганы и погребения раннесарматской культуры встречаются на всей территории бассейна р. Есауловский Аксай, начиная с ее верховий (могильник Абганерово V) и заканчивая нижним течением (могильники: Ромашкин II, Приморский I). Но основной массив раннесарматских комплексов $(81,8 \%)$ сосредоточен на небольшом участке среднего течения р. Есауловский Аксай в могильниках Жутово, Терновский, Ковалевка, Аксай I и Перегрузное. Единственным могильником, содержащим группу раннесарматских погребений, выходящим за пределы выделенного участка, является Аксеновский I, но здесь значительная часть погребений раннесарматского времени датируется в рамках IV в. до н.э. и носит синкретический характер.

В среднесарматское время выбор территории для совершения захоронений кардинально не меняется. На территории верхнего течения Есауловского Аксая, и в предыдущий период практически не используемой для погребальных обрядов, на настоящий момент среднесарматских погребений фактически не известно (исключением является погребение 6 кургана 1 Абганерово V). В нижнем течении отмечено небольшое количество погребений среднесарматского периода, исключением является Чиковский курганный могильник. Основная же масса погребений этого периода $(74,17 \%)$ сгруппирована на том же участке среднего течения Есауловского Аксая, что и раннесарматские погребения (могильники Жутово, Терновский, Аксай I, Аксай II, Перегрузное). Следует отметить, что сам выделенный регион неоднороден. Если в могильниках Перегрузное, Аксай I и Аксай II в части среднесарматских погребений наблюдается неразрывная связь с раннесарматской культурой и сохранение традиций предыдущего периода, то в западной части района в могильниках Жутово и Терновский погребения III вв. н.э. имеют вещевой комплекс и яркие черты, присущие среднесарматскому погребальному обряду [2].

В то же время западнее появляется второй участок, на котором создаются среднесарматские курганные комплексы, имеющие специфические особенности. Здесь формируются небольшие курганные группы, состоящие обычно из двух-трех курганных насыпей (Октябрьский I, Октябрьский II, Октябрьский $\mathrm{IV}$, Октябрьский V). Некоторые их этих могильников будут использоваться в дальнейшем в позднесарматский период. Основная масса погребений из этих могильников датируется I в. н.э. и содержит «классический» набор признаков среднесарматского погребального обряда. Интересной особенностью этой группы является и тот факт, что именно в ней обнаружены наиболее богатые среднесарматские захоронения региона, которые связывают с сарматской знатью [6; 7]. Стоит отметить, что именно для этих мертвых создаются отдельные курганные группы за пределами уже имеющихся и использующихся в это время могильников, сформированных в раннесарматский период, тем самым дистанцируясь от основного массива среднесарматских погребений в крупных могильниках. Это наблюдение в полной мере может быть отнесено и к кургану 28 , формально входящему в Жутовский курганный могильник, но на деле отстоящему от его северо-западной оконечности на 
1,35 км. Нужно сказать, что богатые среднесарматские погребения известны и в могильниках Перегрузное, Аксай III и др., большинство из которых разграблены.

Следует отметить, что подобное «отделение» было отмечено и в раннесарматский период в том же Жутовском курганном могильнике, где курган 27, в нескольких раннесарматских погребениях которого были обнаружены импортные изделия, золотые украшения и парадные мечи [8], также стоит обособленно от основной курганной группы на расстоянии 752 м от крайнего в группе кургана [12].

Необходимость такого отделения части погребенных и создания для них отдельных могильных групп могло определяться несколькими факторами: как социальным статусом погребенных, так и этнокультурной ситуацией в регионе, ведь в части среднесарматских комплексов, находящихся в крупных курганных группах, продолжают сохраняться раннесарматские традиции [2].

В позднесарматский период, так же как и на предыдущих этапах, продолжают использоваться курганные могильники среднего течения Есауловского Аксая, такие как Перегрузное, Жутово, Аксай II. Отдельные позднесарматские погребения встречаются и в могильниках нижнего течения Есауловского Аксая.

Но территория расположения активно используемых могильников меняется, и основные памятники позднесарматской культуры сосредоточиваются в верхнем течении Есауловского Аксая, где находится 69,1\% всех позднесарматских погребений региона. В этом районе формируются новые могильники Абганерово II и Абганерово IV. В это же время создается и небольшой могильник Октябрьский III, состоящий всего из двух курганных насыпей, погребения которого можно датировать второй половиной III в. н.э.

Особенностью использования могильников в позднесарматский период является и то, что на большинстве крупных памятников, расположенных в бассейне реки Есауловский Аксай, функционировавших в ранне- и среднесарматские периоды, последние погребения раннего железного века можно датировать не позднее первой половины III в. н.э. В то же время могильники, не связанные с предыду- щими этапами сарматской культуры (Абганерово II, Абганерово IV), продолжают функционировать до конца сарматской эпохи и именно в них сосредоточено подавляющее большинство погребений, датируемых второй половиной III - IV в. н.э.

Таким образом, носители каждой из трех сарматских культур имели собственные «предпочтения» в выборе места для захоронения своих соплеменников. Такой выбор мог быть обусловлен как определенными географическими факторами, так сакральными традициями; как этнополитической ситуацией в регионе, так и нежеланием отдельных групп «смешивать» своих мертвых с погребенными предшествующих периодов.

\section{ПРИМЕЧАНИЕ}

${ }^{1}$ Исследование выполнено при финансовой поддержке РФФИ и Администрации Волгоградской области, проект № 16-11-34008 «Сарматы Есауловского Аксая: инновации и преемственность погребальных традиций».

\section{СПИСОК ЛИТЕРАТУРЫ}

1. Коробкова, Е. А. История изучения археологических памятников бассейна реки Есауловский Аксай / Е. А. Коробкова // Вестник Волгоградского государственного университета. Серия 4 , История. Регионоведение. Международные отношения. 2011. - № 1. - C. 146-154.

2. Коробкова, Е. А. Особенности погребального обряда среднесарматских памятников Есауловского Аксая / Е. А. Коробкова // Вестник Волгоградского государственного университета. Серия 4, История. Регионоведение. Международные отношения. -2015 . - № 5. - C. 79-84. - DOI: http://dx.doi.org/ 10.15688/jvolsu4.2015.5.8.

3. Курганный могильник Перегрузное I: результаты междисциплинарных исследований / М. А. Балабанова [и др.]. - Волгоград : Изд-во Волгогр. филиала ФГБОУ ВПО РАНХиГС, 2014. - 360 с.

4. Максименко, В. Е. Савроматы и сарматы на Нижнем Дону / В. Е. Максименко. - Ростов н/Д : Издво Рост. ун-та, 1983. -224 c.

5. Мещеряков, Д. М. Топография и перспективы планиграфического изучения среднесарматских могильников Южного Приуралья / Д. М. Мещеряков // Материалы II Международного симпозиума «Степи Северной Евразии: стратегия сохранения природного разнообразия и степного при- 
родопользования в XXI веке». - Оренбург : Газпромпечать, 2000. - С. 132.

6. Мордвинцева, В. И. Курганы сарматской знати у поселка Октябрьский / В. И. Мордвинцева, Е. П. Мыськов // Археологические вести. - 1999. № 6. - C. 179-191.

7. Мыськов, Е. П. Погребения сарматской знати с Есауловского Аксая / Е. П. Мыськов, А. В. Кияшко, А. С. Скрипкин // Нижневолжский арехеологический вестник. - 1999. - Вып. 2. - С. 149-167.

8. Скрипкин, А. С. Жутовский курган № 27 сарматского времени в Волго-Донском междуречье / А. С. Скрипкин, О. А. Шинкарь // Российская археология. -2010. - № 1. - С. 125-137.

9. Файферт, А. В. Топография, способы возведения и количественные характеристики курганов эпохи бронзы на территории бассейнов Дона и Маныча / А. В. Файферт // Вестник Калмыцкого института гуманитарных исследований РАН. 2015. - № 1. - C. 47-53.

10. Черных, Л. А. Курганы эпохи энеолитабронзы междуречья Базавлука, Соленой, Чертомлыка / Л. А. Черных, М. Н. Дараган - К. : Изд. Олег Филюк, 2014. - 568 c.

11. Шилов, В. П. Курганы скифской эпохи из могильников Аксеновский І-ІІ / В. П. Шилов, М. А. ОчирГоряева // Памятники предскифского и скифского времени на юге Восточной Европы (МИАР, № 1). - М. : [б. и.], 1997.- С. 127-152.

12. Шилов, В. П. Отчет о работах Астраханской экспедиции за 1964 г. / В. П. Шилов // Архив ИА PAH. - P-1, № 3156, 3156a.

13. Яценко, С. А. К изучению планиграфии крупных сарматских некрополей / С. А. Яценко // Константин Федорович Смирнов и современные проблемы сарматской археологии : материалы IX Междунар. научн. конф. «Проблемы сарматской археологии и истории». - Оренбург : Изд-во Оренбург. гос. пед. ун-та, 2016. - С. 311-319.

\section{REFERENCES}

1. Korobkova E.A. Istoriya izucheniya arkheologicheskikh pamyatnikov basseyna reki Esaulovskiy Aksay [The History of Studying Archaeological Monuments in the Esaulovsky Aksai River]. Vestnik Volgogradskogo gosudarstvennogo universiteta. Seriya 4, Istoriya. Regionovedenie, Mezhdunarodnye otnosheniya [Science Journal of Volgograd State University. History. Area Studies. International Relations], 2011, no. 1, pp. 146-154.

2. Korobkova E.A. Osobennosti pogrebalnogo obryada srednesarmatskikh pamyatnikov Esaulovskogo Aksaya [Features of Funeral Rite of Middle Sarmatian Monuments of Esaulovsky Aksai
River]. Vestnik Volgogradskogo gosudarstvennogo universiteta. Seriya 4, Istoriya. Regionovedenie, Mezhdunarodnye otnosheniya [Science Journal of Volgograd State University. History. Area Studies. International Relations], 2015, no. 5, pp. 79-84. DOI: http://dx.doi.org/10.15688/jvolsu4.2015.5.8.

3. Balabanova M.A., Pererva E.V. Kurgannyy mogilnik Peregruznoe I: rezultaty mezhdistsiplinarnykh issledovaniy: monografiya [Peregruznoe I Burial Mound: Results of Interdisciplinary Research]. Volgograd, Izdvo Volgogradskogo filiala FGBOUVPO RANHiGS, 2014. $360 \mathrm{p}$.

4. Maksimenko V.E. Savromaty $i$ sarmaty na Nizhnem Donu [Sauromatians and Sarmatians on the Lower Don]. Rostov-on-Don, Izd-vo Rostovskogo unta, $1983.224 \mathrm{p}$.

5. Meshcherikov D.M. Topografiya i perspektivy planigraficheskogo izucheniya srednesarmatskikh mogilnikov Yuzhnogo Priuralya [Topography and Prospects of Planning Study of Middle Sarmatian Burial Mounds of the Southern Urals]. Materialy II Mezhdunarodnogo simpoziuma «Stepi Severnoy Evrazii: Strategiya sokhraneniya prirodnogo raznoobraziya i stepnogo prirodopolzovaniya $v$ $X X I$ veke» [Materials of the $2^{\text {nd }}$ International Symposium "Steppes of Northern Eurasia: A Strategy for Conservation of Natural Diversity and Steppe Nature Management in the $21^{\text {st }}$ Century"]. Orenburg, IPK "Gazprompechat",, 2000, pp. 132.

6. Mordvintseva V.I., Myskov E.P. Kurgany sarmatskoy znati u poselka Oktyabrskiy [Barrows of the Sarmatian Nobility near the Village of Oktyabrsky]. Nosov E.N., ed. Arkheologicheskie vesti. № 6 [Archaeological News. no. 6]. Saint Petersburg, Izd-vo "Dmitry Bulanin", 1999. pp. 179-191.

7. Myskov E.P., Kiyashko A.V., Skripkin A.S. Pogrebeniya sarmatskoy znati s Esaulovskogo Aksaya [Burials of the Sarmatian Nobility from Esaulovsky Aksai River]. Nizhnevolzhskiy arekheologicheskiy vestnik. Vyp. 2. [Lower Volga Archaeological Bulletin. Iss. 2]. Volgograd, Izd-vo VolGU, 1999, pp. 149-167.

8. Skripkin A.S., Shinkar O.A. Zhutovskiy kurgan № 27 sarmatskogo vremeni v Volgo-Donskom mezhdurechye [Zhutovsky Barrow no. 27 of the Sarmatian time in the Volga-Don Interfluve]. Rossiyskaya arkheologiya, 2010, no. 1, pp. 125-137.

9. Fayfert A.V. Topografiya, sposoby vozvedeniya i kolichestvennye kharakteristiki kurganov epokhi bronzy na territorii basseynov Dona i Manycha [Topography, Methods of Erection and Quantitative Characteristics of Barrows of the Bronze Age in the Basins of the Don and Manych Rivers]. Vestnik Kalmytskogo instituta gumanitarnykh issledovaniy RAN, 2015, no 1, pp. 47-53.

10. Chernykh L.A., Daragan M.N. Kurgany epokhi eneolita-bronzy mezhdurechya Bazavluka, Solenoy, Chertomlyka: monografiya [Barrows of the 
Bronze Age of Bazavluk, Solenaya, Chertomlyka Rivers: Monograph]. Kaliningrad, Izdatel Oleg Filyuk, 2014. 568 p.

11. Shilov V.P., Ochir-Goryaeva M.A. Kurgany skifskoy epokhi iz mogilnikov Aksenovskiy I-II [Barrows of the Scythian Epoch from Aksenovsky I and Aksenovsky II Burial Mounds]. Pamyatniki predskifskogo $i$ skifskogo vremeni na yuge Vostochnoy Evropy [Monuments of pre-Scythian and Scythian Time in the South of Eastern Europe]. Moscow, 1997, no. 1, pp. 127-152.

12. Shilov V.P. Otchet o rabotakh Astrakhanskoy ekspeditsii za 1964 g. [Report on the Work of the Astrakhan Expedition for 1964]. Arkhiv IA RAN
[Archive of the Institute of Archeology of the Russian Academy of Sciences], R-1, no. 3156, 3156a.

13. Yatsenko S.A. K izucheniyu planigrafii krupnykh sarmatskikh nekropoley [To the Study of the Planning of Large Sarmatian Necropolises]. Konstantin Fedorovich Smirnov i sovremennye problemy sarmatskoy arkheologii. Materialy IX Mezhdunarodnoy nauchnoy konferentsii «Problemy sarmatskoy arkheologii i istorii» [Konstantin Smirnov and Modern Problems of Sarmatian Archaeology. Materials of the $9^{\text {th }}$ International Scientific Conference "Problems of Sarmatian Archaeology and History"]. Orenburg, Izd-vo Orenburgskogo gos. pedagog. un-ta, 2016, pp. 311-319.

\section{Information About the Author}

Elena A. Korobkova, Assistant Professor, Department of Archaeology, Foreign History and Tourism, Volgograd State University, Prosp. Universitetsky, 100, 400062 Volgograd, Russian Federation, elena.korobkova@volsu.ru, adsi@volsu.ru,http://orcid.org/0000-0001-9742-8000

\section{Информация об авторе}

Елена Алексеевна Коробкова, старший преподаватель кафедры археологии, зарубежной истории и туризма, Волгоградский государственный университет, просп. Университетский, 100, 400062 г. Волгоград, Российская Федерация, elena.korobkova@volsu.ru, adsi@volsu.ru, http://orcid.org/ 0000-0001-9742-8000 